\title{
INTERNET EXCHANGE POINTS
}

\section{Stefan Radovanović, Stefan Janićijević, Dalibor Radovanović, Marko Šarac}

Fakultet za informatiku i računarstvo, Univerzitet Singidunum, Beograd, Srbija
Correspondence:

e-mail:

stefan.radovanovic.10@singimail.rs

\section{Rezime:}

Internet današnjice sastoji se od preko 50.000 mreža koje su pod kontrolom privatnih lica. Zajedno ove mreže pružaju mogućnost globalnog povezivanja. Da bi povezanost u današnjem svetu u startu bila moguća, ove mreže moraju međusobno da komuniciraju. Upravo tu dolazimo do pojma Internet exchange point (IXP), preko kojeg dobijamo tehničke mogućnosti da se mreže povezu i razmene podatke. U ovom radu pokazaćemo merenja koja dokazuju kako IXP imaju pozitivan efekat na performansu mreže. Takođe, objasnićemo korake startovanja jednog IXP-a.

Ključne reči:

internet exchange point, internet, ISP.

\section{INTRODUCTION TO IXP}

Internet exchange Point (IXP) je infrastruktura koju koriste internet provajderi (ISP) za razmenjivanje saobraćaja između njihovih autonomnih sistema (AS). IXP omogućava internet provajderu interkonekciju sa AS direktno, tj. uspostavljanje direktne veze između njih kao alternativa korišćenju third-party mreža. IXP igraju krucijalnu ulogu u razvoju interneta jer kreiranjem guste mreže interkonekcija po niskoj ceni ohrabruju internet provajdere da koriste ovu metodu. Neki od provajdera poseduju protok od nekoliko Tbit/s i smatraju se najvažnijim članicama današnjeg interneta [1].

Opšte je prihvaćeno da je peerovanje na IXP vrlo korisno, gledano sa strane performansi. Na primer, kraći putevi poboljšavaju kašnjenje povratnog puta (Round-trip) i lokalizaciju samog saobraćaja. Međutim, zbog malog broja literature i studija nije posebno naglašeno kolika je ušteda u ceni i performansama prilikom upotrebe IXP-a. Neki od eksperimenata koji su sprovedeni na italijanskom IXP-u pokazaće koliko je zapravo poboljšanje prilikom upotrebe tačke za razmene podataka [2].

Studija će pokazati koliko je IXP efektivan u obezbeđivanju da internet saobraćaj ostane lokalnog karaktera tako što će se proveriti preko kojih zemalja je putovala konekcija. Kao što je rečeno, studija je fokusirana na Italiju, gde se nalaze izvorni AS i ciljni AS koji su i cilj merenja. Najviše je pažnje obraćeno na dva najpopularnija italijanska IXP-a: Milanski 
Internet Exchange (MIX) i Nautilus Mediterranean Exchange Point (NaMeX). U okviru studije su ,takođe, uključena i tri IXP-a srednje veličine zbog aktivne kontrole BGP „objava” i prisiljavanja internet saobraćaja da uzima druge rute za pravilno upoređivanje. Eksperiment se bazirao na merenjima mrežne metrike: vreme povratnog puta (RTT), broj skokova, gubici u paketima itd. Za ovaj sistem merenja korišćen je RIPE Atlas, koristeći sonde koje su isključivo locirane u Italiji, kojih trenutno broji oko 150 .

Izvedene su dve vrste eksperimenata koje su nazvane, respektivno, Kritični internet servisi (CIS) i Selektivne BGP objave (SBA).

\section{KRITIČNI INTERNET SERVISI (CIS)}

U prvom eksperimentu, mrežni eksperimenti su isprojektovani u cilju mogućeg uvida u QoS povezanog sa kritičnim veb-sajtovima za italijanske klijente. Koncept je bio da se pribavi klasifikacija rezultata u skladu sa razlikom da li je klijent povezan na IXP ili nije. Odabrana su dva seta internet veb-stranica koje se mogu smatrati za najznačajnije među italijanskim korisnicima. Prva grupa veb-sajtova, koji su nazvani „Kritično” povezana je sa kritičnom infrastrukturom, dok je druga grupa veb-sajtova „Posećeno” vezana za popularne sajtove. „Kritično” se sastoji iz sledećih kategorija: onlajn bankarstvo, osiguravajuće kompanije, javna administracija, veb-mail provajderi i drugo. Drugi set veb-sajtova čini 100 najposećenijih italijanskih sajtova, prema rangu od strane „Alexa” [3].

Sledeći grafikoni pokazuju RTT za skup podataka od grupe veb-sajtova „Kritično”, kao i broj skokova za grupu sajtova „Posećeno”. Krive pokazuju da sonde koje putuje preko IXP-a poseduju bolje indikatore i statistiku. $\mathrm{Na}$ primer, RTT za oko 70\% sondi koje putuje preko IXP-a iznosi $30 \mathrm{~ms}$ ili manje, dok samo $20 \%$ ima iste performanse za sonde koje ne putuju preko IXP-a.

Konačno, podaci koji su kolektovani u CIS eksperimentu mogu biti analizirani u pogledu bezbednosti kritičnih veb-servisa sa njihovim dolaznim internet saobraćajem. Nedavni slučajevi špijunaže internet saobraćaja prisililo je vlade da istraže da li je saobraćaj generisan od strane njihovih građana, i da li je saobraćaj koji je išao ka kritičnim servisima ostao u potpunosti lokalno duž puta. Jasno je da ako je saobraćaj ostao u zemlji, tj. ako je ostao lokalnog karaktera, ne može biti dovoljan garant za bezbednost saobraćaja, ali su vlade vrlo osetljive na ovo pitanje.
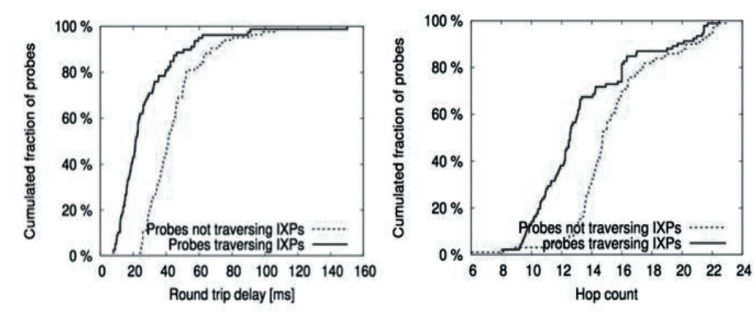

RTT za kritične veb-sajtove (levo) i broj skokova za set najposećenijih sajtova (desno)

Sledeće merenje koje je izvršeno jeste koliko frekventno uz pomoć IXP-a može doći do italijanske destinacije sa lokalnog izvora, bez upotrebe tranzita većeg provajdera koji nije iz Italije. Kvantitativno je provereno da li MIX i NaMeX efektivno čuvaju lokalni internet saobraćaj lokalno.

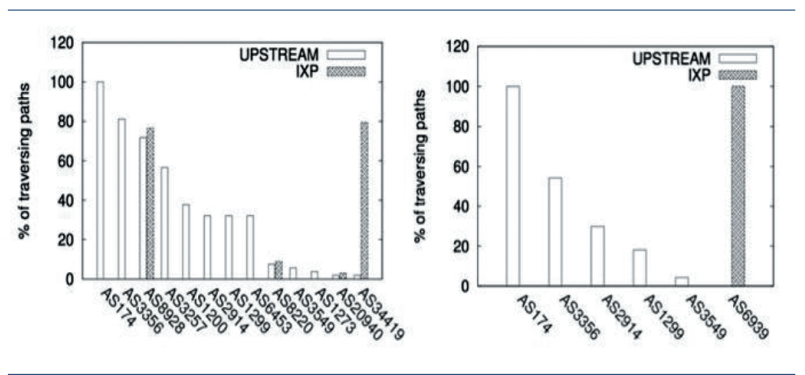

U skladu sa determinisanjem države gde se nalazi AS, kojeg ćemo nazvati X, pitan je RIPEstat servis koji se bavi internet merenjima i analizama za prefikse koje je X objavio i državama čiji ovi prefiksi odgovaraju. Ako su vraćeni prefiksi svi bili asocirani sa istim zemljom, onda možemo da zaključimo da je u tom zemlji lociran $X$. U drugom slučaju, za određivanje zemlje potrebno je manuelno uzeti meta podatke iz X, gledajući, na primer, veb-sajt odgovarajućeg provajdera. U većini slučajeva, strani AS zaobilazi se samo kada se upotrebljava ruta većeg provajdera, što potvrđuje koliko je IXP efektivan u prezervaciji lokalnog saobraćaja.

Ovi rezultati se moraju uzeti u obzir vrlo pažljivo zbog 3 razloga:

1. Dva CDF-a referisana su na razjedinjene setove sonde, jer je svaka sonda prošla ili kroz IXP, ili ne.

2. RTTovi i brojevi skokova referišu na poslednji skok koji je odgovorio našim merenjima, što vrlo često nije stvarna meta (40/53 za set podataka „Kritično”, 59/94 za set podataka „Poseta”).

3. Ruter u IXP-u može odgovoriti na tracerouteu koristeći interfejs koji se ne nalazi na peering 
LAN-u, što može dovesti do pogrešno zavedene korespondevane traceroute. Podaci sa brojača skokova mogu biti pod uticajem postojanja tunela.

Konkluzija je da nam grafikoni koje smo naveli da dobijemo prve pozitivne eksperimentalne impresije o uticaju IXP-a. Sledeći eksperiment koji je izvršen ne sadrži probleme na koje smo ukazali iznad.

\section{SELEKTIVNE BGP OBJAVE (SBA)}

Drugi eksperiment vezan je za analizu alternativnih rutiranja koje uključuje ili IXP, ili upstream korišćen od strane italijanskih internet provajdera sa ciljem dolaska na internet servis. Partnerstvo sa „MC-link”, „Seeweb” i „Unidata” internet provajderima, koji spadaju u red provajdera srednje veličine u Italiji, bila je preparacija za eksperiment koji je podrazumevao da se svakome od navedenih provajdera dostavlja rezervacija jednog IP subneta i jednog servera sa centrom podataka. Svakom serveru je dodeljena IP adresa koja je proistekla iz rezervisanog IP subneta. Konfiguracija je glasila da tačno rukuje i odgovara zahtevima za ICMP echo sa pingovima i traceroute-ama. Za svakog provajdera su izvršeni opisani koraci u drugačijem vremenskom okviru. Internet provajderi su zamoljeni da naglase predodređenu sekvencu narednih 5 BGP ažuriranja koje se odnose na rezervisane IP subnet-ove. Svako ažuriranje trajalo je četiri sata, sa totalnom sumom od 20 sati po testu [3]. Lista BGP ažuriranja je napravljena sa razlogom selektivnog distribuiranja ruta na različite sub-setove dostupnih ulaza, pridržavajući se šeme:

- „UPSTREAM” - objaviti samo ako se prenosi AS;

- „IXPS” - objaviti samo za MIX i NaMeX članove;

- „MIX” - objaviti samo za MIX članove;

- „NAMEX” - objaviti samo za NaMeX članove;

- „ALL” - objaviti za sve članove.

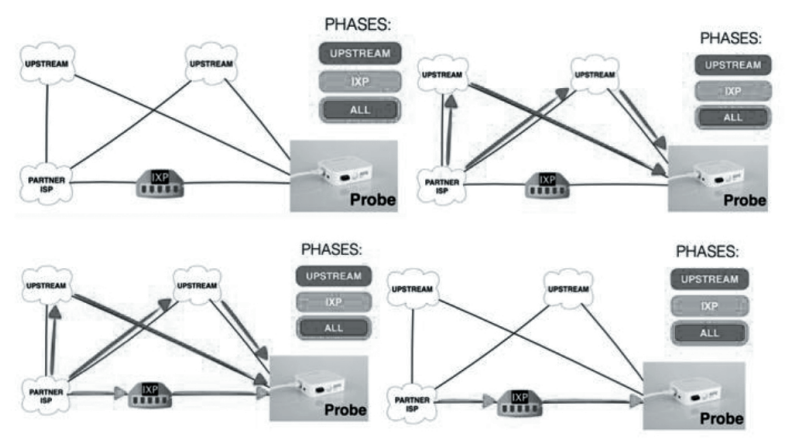

Faze Selektivne BGP objave
Za eksperiment SBA pokrenulo se odabiranjem subsetova za sonde koje su mogle da dođ u do cilja tokom oba „UPSTREAM” intervala, i tokom barem jednog „MIX” i „NAMEX” intervala. Probe koje su odabrane omogućile su nam da izmerimo razliku između povezivanja koje nude IXP i koje nude ISP.
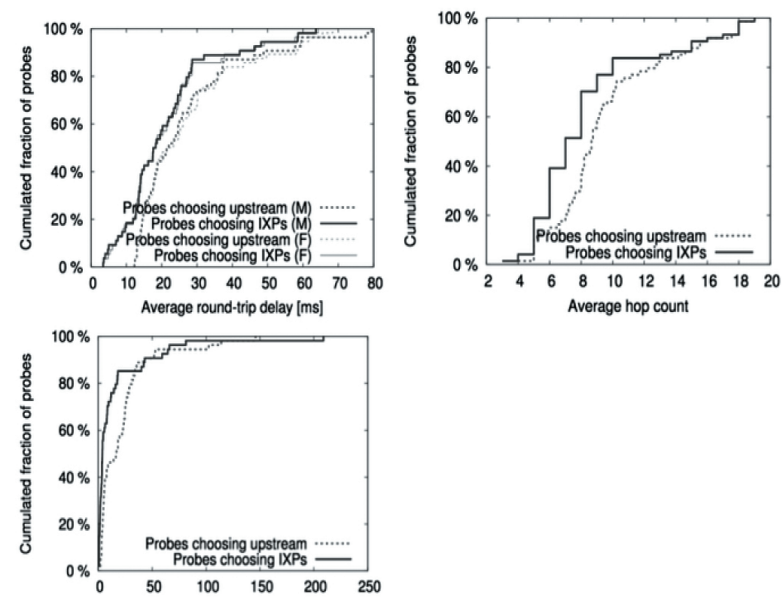

RTT zastoji tokom eksperimenata sa Seewebom, broj skokova sa MC-linkom i jitter sa UniDatom

Grafici pokazuju zastoj povratnog puta izmeren tokom eksperimenta sa Seewebom, broj skokova tokom eksperimenata sa MC-linkom i jitter-a izmerenog u UniDati. Kao primer, prvi grafik sastoji se iz 4 krive koje pokazuju distribuciju prosečnog RTT-a za sve Seeweb mete, u oba slučaja kada je meta pokušavala da se kreće preko IXP-a ili upstream-a. Grafikoni pokazuju da putevi preko IXP-a kao medijuma uvek pokazuju iste ili bolje performanse nego put preko upstream provajdera.

Tokom eksperimenta primetili smo da putanje duž upstream-a pokazuju sasvim drugačije vrednosti indikatora performansi. Gledajući prikupljenu traceroutu tokom upstream intervala, otkrivena je ruta za svakog od provajdera. Ovo je lista upstream-ova koja su nađena:

- MC-link (AS3257, AS12874, AS174, AS3356, AS35612, AS57329)

- Seeweb (AS3257, AS174, AS3549, AS3356)

- Unidata (AS3257, AS12874, AS16004, AS24796, AS20836)

AS-ovi su bili raspoređeni u 3 klase:

1. Klijenti koji reprezentuju razne organizacije, univerzitete i kompanije itd;

2. Tranzitni internet provajderi koji omogućavaju pristup internetu i tranzitnim servisima. Krajnji cilj tranzitnih internet provajdera je da povećaju 
klijentsku bazu u njihovoj zoni i da smanje troškove korišćenja upstream tranzita pomoću selektivnog peeringa sa ISP.

3. Content/Access/Hosting provajderi (CAH) su internet provajderi koji nude internet pristup i/ ili serverski hosting. Njihovi klijenti su rezidencijalni potrošači ili kompanije bez AS broja, dok su njihovi klijenti za serverski hosting uglavnom content/service provajderi, takođe bez AS broja.

Sledeća dva grafikona, respektivno, bazirana su na prosečnom RTT i broju skokova koji su se dogodili u SBA eksperimentu na meti Seeseb Milan. Svaki grafikon sadrži tri krive, svaka je vezana za jednu AS klasu.
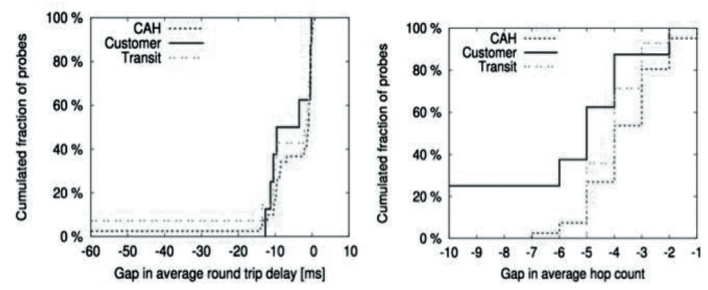

Prosečan RTT (levo) i prosečan broj skokva (desno) za Seeweb Milan tokom SBA eksperimenta

Kriva je CDF koja pokazuje distribuciju performansnih praznina izvedenih iz komparacije indikatora performansi između puteva koji putuju preko IXP-a, i puteva koji ih izbegavaju. Klijent je uzet sa klasom manjih mreža i kućnih potrošača. Možemo videti da oni najviše dobijaju od upotrebe IXP-a. Tako da se može zaključiti da Internet Exchange Point najviše benfita donose upravo kućnim korisnicima.

\section{POKRETANJE NOVOG IXP-A}

Nije moguće definisati određeni skup instrukcija za pokretanje IXP. Svaki novi IXP suočiće se sa različitim izazovima i radiće pod različitim ekonomskim, tehničkim i pravnim okolnostima [6].

Pitanja koja treba postaviti pre pocetka:

- Da li postoji potreba za novim IXP?

- Da li su korisnici spremni za povezivanje i da plate?

- Koja organizacija treba biti postavljena za vođenje IXP-a?

- Kako započeti IXP sa malo ili nimalo novca i rasporedi snažan infrastruktura prvog dana?
- Koje usluge treba voditi?

- Ljudski resursi potrebni za upravljanje IXP?

- Kako da budemo sigurni da će IXP trajati?

- Kako se širiti i dovoditi nove korisnike?

\section{Izazovi na počektu}

Najteži deo sa uspostavljanjem IXP-a nije tehnički deo, nego izgradnja zajednice i poverenje. Takođe, IXP mora biti održiv nakon faze uspostavljanja [7]. Ovo uključuje da ima dovoljno sredstava za rad i unapređivanje opreme u budućnosti, razvojem tehnologije i rasta saobraćaja. Članovi plaćaju naknadu na osnovu njihove veličine porta, tako da je jedna taksa za 1 GE port i jedna za 10 GE porta. Ovo se ne zasniva na stvarnom saobraćaju, vec na brzini porta. Novi IXP su skloni da veruju da je dobra ideja da ponude besplatne priključke clanovima sa velikim sadržajem mreža kako bi privukli druge članove. Na prvi pogled, ovo možda izgleda kao dobra ideja, ali brzo će se naći stisnuti između vlasnika velikog mrežnog sadržaja i broadband operatera, koji takođe žele svoj port besplatno. Generalno, bolje je jednako naplatiti i tretira sve jednako. To može učiniti malo teže da IXP krene, ali svakako čini održavanje IXP lakše na duge staze. Većina vlasnika velikih sadržaja takođe podržavaju nove IXP koji se formiraju u mestima ili regionima u kojima ne postoji IXP.

\section{Institucionalni i operativni modeli za IXP}

Usvojeni su razni institucionalnih modela za rad IXP [8]. Oni spadaju u četiri kategorije:

- Neprofitne industrije udruženja ISP-a;

- Operator-neutralna, komercijalna i za-profit preduzeća;

- Univerzitetske i vladine agencije;

- Neformalna udruženja mreža.

Većina evropskih IXP-a izraslo je iz nekomercijalnih organizacija, kao što su istraživačke organizacije .

Većina afričkih IXP-a osnovano je od strane ISP udruženja i univerziteta.

U Sjedinjenim Američkim Državama većina IXP-a su komercijalni, a neki komercijalni IXP su se pojavili i u Evropi.

\section{IXP Neutralnost:}

Mnogi ISP izrazili su snažna osećanja o značaju neutralnosti IXP-a, a većina velikih evropskih IXP-a pripisuju svoje uspehe svojoj neutralnosti. 


\section{Vlasništvo:}

Neutralnost bi mogla biti ugrožena ako ISP član poseduje delove (kao što su oprema itd.) IXP opreme i stiče preko drugih organizacija.

Mnogi IXP započeti su sa donacijama opreme, rack prostora, radnika i druge pomoći. To je deo kooperativne prirode većine početnih IXP. U slučaju donacija, sponzori treba da stave u pisanoj formi prirodu sporazuma za IXP, da koristi opremu.

\section{Lokacija}

Pored stvaranja zajednice koja će podržiti IXP, drugi važan faktor za uspostavljanje uspešnog IXP-a je njegova lokacija. Pronalaženje adekvatne lokacije koja je neutralana i jeftina veoma je bitno. Prilikom razmatranja mogućih lokacija, sledeći elementi treba da budu uzeti u račun: prostor, kontrola životne sredine, bezbednost, pouzdanost i redundantno napajanje, pristup zemaljske infrastrukture, kablova, i podrška. Odlučivanje o lokaciji verovatno će obuhvatiti procenu postojećih objekata koji se mogu koristiti, a zatim u odnosu na potencijalne opcije lokacije na troškove i trud koji su uključeni u formiranje novog samostalnog objekta. U mnogim zemljama troškovi u vezi sa zakupom prostora, finansijskih sredstava i osoblja zapošljavanja mogu biti visoki. Pored lakšeg pristupa infrastrukture, data centar takođe treba da obezbedi stabilno napajanje, ili vam je potrebno kako bi se osiguralo da imate UPS-eve (Uninterruptible Power Supply) i možda čak i agregate. Takođe, proverite da li postoji prostor za rast IXP. Možda početi samo sa dva rack-a (ormana), ali ako je IXP uspešan možda će biti potrebno više, a pomeranje IXP je uvek teško.

\section{IXP Oprema i Usluge}

- Ethernet Switch (Obavezno)

- Jezgro svakog IXP-a je Ethernet Switch;

- Ulaganje u opremu koja je najbolja i najviše može da proširi koje finansije dozvoljavaju;

- Imati 2 switch-a je uvek dobro, ako sredstva mogu da dozvole.

- Adresni prostor (Obavezno)

- IXP će zahtevati IP adresni prostor za peering.

- Route server (Opciono)

- Tokom početnih faza podešavanja, imati route server obezbeđuje lakoću konfiguracije novih članova.
- Veb i Mail serveri (Opciono)

- Transit Router (Opciono)

- Route Collector (Opciono)

- Takođe se naziva looking glass, koji pomaže članovima IXP-a prilikom rešavanja problema. Može se koristiti za prikupljanja ruta za merenja.

Postoji veliki broj osnovnih usluga koje IXP može da ponuditi svojim članovima izvan zajedničkog povezivanja. Ove usluge se razlikuju kod svakog IXP-a i ni na koji način se ne takmiče sa svojim članovima [4].

Pružaoci drugih usluga, koje nisu mrežni operatori, mogu se povezati u IXP, uključujući i:

- pružaoci keša sadržaja (CDN);

- DNS root serveri;

- country code top-level domain (ccTLD) name server instances;

- vremenski serveri;

- Looking Glass ili Routeview serveri.

Davaoci ostalih usluga mogu biti privatna preduzeća, nevladine organizacije (NVO), vladine mreže, ili sama IXP operater. Kao i mrežnih operatera, davaoci drugih usluga moraju da instaliraju i održavaju svoju opremu u IXP-u i moraju da podržavaju svoje usluge.

\section{Osoblje IXP- $a$}

Koliko zaposlenih je potrebno jednom IXP-u [5]?

- 1 do 3 finansijski održiv (čak i na početku)

- Nemogućnost da se održi 24/7 NOC;

- IXP više zavisi od opreme nego što zavisi od ljudi.

- 5+ finansijski održiv samo ako je IXP porasla za pružanje više usluga, onda puka IXP

- Sposobnost da održe kvalitet I korisničku podršku i brzo reakciono vreme u hitnim slučajevima (24/7 NOC).

\section{IXP Website}

U većini slučajeva IXP veb-strana je njegov prvi kontakt i referentna tačka za sve zainteresovane stranke.

Oni koji dolaze na sajt IXP-a spadaju pod 4 kategorije:

1. Potencijalni IXP učesnici;

2. Trenutni IXP članovi;

3. Javnost;

4. IXP osoblje. 


\section{Potencijalni IXP učesnici}

Najvažnije ciljna grupa. Većina IXP-a je u potrazi za povećanjem njihovog IXP-a sticanjem dodatnih i vrednih učesnika.

Važne informacije za ovu grupu su:

- Ko su sadašnji učesnici IXP-a?

- Iznos saobraćaja koji se razmjenjuje na IXP-u;

- Tehnička podešavanja i pravila;

- Troškovi priključka;

- Postupak povezivanja;

- Kontakt informacije i pitanja.

\section{Trenutni IXP članovi}

Ova grupa će često posećivati sajt IXP-a i važne informacije ovoj grupi uključuju:

- Peering informacije i alati;

- Grafikoni upotrebe, statistika, topologija mreže;

- 24h kontakt informacije;

- Stalne informacije razvoja na IXP-u (novi članovi, planirano održavanje, tehnički sastanci itd.).

\section{Javnost}

Istraživači koji su se zainteresovali za internet i IXP širom sveta. U principu, oni traže statistike i kretanje saobraćaja koji se razmenjuju na IXP-u. Ostale informacije vezane za IXPk, kao što je IXP godina osnivanja, brend Switch-a koji se koristi, pružene usluge i još mnogo toga.

Pored toga, drugi neistraživači mogu biti u potrazi za više informacija, kao što su:

- Šta je IXP?

- Osnovne informacije o IXP-u (istorija);

- Status IXP-a dana.

\section{IXP Osoblje}

Kako IXP raste, veb-sajt IXP-a postaje korisna alatka za komunikaciju za:

- Tehničko osoblje i inženjere;

- Administraciju i finansijski menadžment;

- Prodaju i marketing;

- Nadzor menadžment i izveštavanje.

\section{ZAKLJUČAK}

Internet Exchange Point, od samog trenutka nastanka, pa do danas, imao je za cilj optimizaciju internet konekcije između međusobno povezanih članova globalne mreže. Teoretski i empirijski dokazi argumentuju važnost IXPa. U ranim fazama, IXP je pomogao lokalnim internet provajderima da smanje troškove internacionalnog tranzita i poboljšaju kvalitet usluge.

Internet provajderi imaju niže operativne troškove jer je razmena lokalnih podataka daleko jeftinija od IP tranzita. Samim tim, krajnji korisnici plaćaju manju pretplatu internet provajderima. Rezultat smanjenja troškova dovodi do veće kupovina kompjuterskog hardvera i softvera zbog veće iskorišćenosti. U radu je predstavljena kritična važnost Internet Exchange Point-a na današnji internet, a samim tim i današnji svet koji u sve većoj meri zavisi od globalne povezanosti.

\section{LITERATURA}

[1] https://www.itu.int/en/wtpf-13/Documents/backgrounder-wtpf-13-ixps-en.pdf

[2] https://arxiv.org/ftp/arxiv/papers/1307/1307.5264. pdf

[3] https://labs.ripe.net/Members/roberto_di_lallo/isit-really-worth-peering-at-ixps

[4] https://www.internetsociety.org/sites/default/files/ Global\%20IXPToolkit_Collaborative\%20Draft_ Feb\%2024.pdf

[5] https://meetings.ripe.net/see5/files/SOX\%20at\%20 SEE5\%20-\%20TIRANA\%202016\%20-\%20Presentation\%20FINAL.pdf

[6] https://blog.apnic.net/2016/11/23/start-internetexchange-point/

[7] https://www.linkedin.com/pulse/how-do-i-startinternet-exchange-point-kurt-erik-kurtis-lindqvist

[8] https://www.ixptoolkit.org/content/ixp-models 


\title{
INTERNET EXCHANGE POINTS
}

\begin{abstract}
:
The Internet of today is made of over 50,000 networks that are controlled by private owners. Together, these networks provide opportunities for global connectivity. To make connections possible in today's world, these networks must communicate with each other. It is here that we come to the concept of Internet exchange point (IXP) through which we get the technical ability to connect networks and exchange data. In this paper we will show measurements that prove that IXPs have a positive effect on network performance. Also we will explain the steps of starting IXP.
\end{abstract}

Keywords:

Internet exchange point, Internet, ISP. 